\title{
Conformational Flexibility and the Interaction of Huperzine $A$ in the Active Site of Acetylcholinesterase: A Quantum Chemical and Charge Density Study
}

\author{
Renuga Parameswari Azhagesan, Saravanan Kandasamy, Kumaradhas Poomani* \\ Laboratory of Biocrystallography and Computational molecular Biology, Department of \\ Physics, Periyar University, Salem 636011, India; renugazhagesan@ @mail.com( R.P.A.); \\ saravanansmtr@gmail.com (S.K.) \\ Correspondence: kumaradhas@yahoo.com; Tel: +91 (0)427 2345520; Fax: +91 (0)4127 \\ 2345565
}

\begin{abstract}
Huperzine A is an herbal reversible inhibitor of Acetylcholinesterase (AChE). A molecular docking analysis on Huperzine A molecule has been carried out to understand its structure, conformational flexibility, intermolecular interaction and the binding affinity in the active site of AChE enzyme. Further, the charge density distribution of huperzine A molecule (lifted from the active site of $\mathrm{AChE}$ ) was determined from the high level quantum chemical calculations coupled with charge density analysis. The binding affinity of Huperzine A towards AChE was calculated from the molecular docking; the lowest docked energy is -8.46 $\mathrm{kcal} / \mathrm{mol}$. In the active site, huperzine A molecule interacts with acyl binding pocket-Phe330 of $\mathrm{AChE}$, that is, the bicyclo ring group of huperzine A forms an intermolecular interaction with the oxygen atom of main chain of the amino acid residue Phe330 at the distances 3.02 and $3.25 \AA$ respectively. On the other hand, a gas phase study on huperzine A molecule also performed using HF and DFT (B3LYP) methods with the basis set 6-311G**. The molecular structure, conformation, and the charge density distribution of huperzine A molecule in the gas phase have determined using quantum chemical calculations and the charge density analysis. The comparative studies between the gas phase and the active site forms of huperzine A molecule, explicitly reveals the degree of conformational modification and the charge density redistribution of huperzine A when present in the active site. The dipole moment of the molecule in the active site is $6.85 \mathrm{D}$, which is slightly higher than its gas phase value (5.91 D). The electrostatic potential (ESP) surface of active site molecule clearly shows
\end{abstract}


the strong electronegative and positive ESP regions of the molecule, which are the expected strong reactive locations of the molecule.

Keywords: huperzine A-AChE; molecular docking; intermolecular interaction; quantum chemical calculation; charge density distribution; atomic charges; dipole moment; electrostatic potential; toxicity analysis

\section{Introduction}

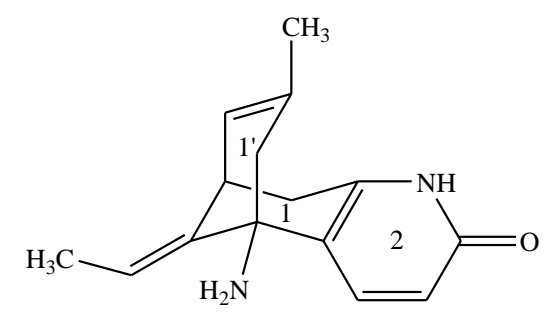

Scheme 1. Chemical structure of Huperzine A

(-)-Huperzine A (Scheme 1) is one of the reported inhibitors of AChE [1]. It is an alkaloid isolated from the club moss [1-10] Huperzia serrata and used as a Chinese herbal medicine. The pharmacologic studies shows that it is a potent reversible inhibitor of acetylcholinesterase exhibits strong anti-cholinesterase activity, which markedly increases the efficiency in learning and memory in animals [2,11-15]. It is a natural, highly selective, reversible, slow and potent inhibitor of $\mathrm{AChE}$, which is being used for the treatment of Alzheimer disease [16-20]. Cholinergic neurodegeneration is the major pathological feature of this disease $[21,22]$. Huperzine A has been used to treat this disease, as it has high potency and low toxicity $[23,24]$. However, the inhibitory activity of the molecule is mainly attributed to the interaction of this small molecule with the neighbouring amino acids present in the active site of $\mathrm{AChE}$, the strength of binding and charge distribution. When the small molecule inhibitor present in the active site of $\mathrm{AChE}$, it interacts with the nearby amino acids of the active site, where its energy changes; in consequence of this effect the molecule adopts a new conformation in the active site. The biological effects are often related to electron density 
distribution of ligand molecule and its orientation, the capability of forming of intermolecular interactions and the electrostatic potential of the molecule in the active site [5].

The binding strength of this molecule largely depends on the electrostatic parameters and the charge complementarities, which leads to conformational change and the charge redistribution of the huperzine A molecule in the active site of the enzyme. The charge distribution allows to understand the electrostatic moments of the molecule in the active site of AChE. Hence, it enables to predict the orientation of the huperzine A inside the active site. In the active site, as the conformation of the molecule changes, its orientation also changes. To precisely understand the active site effect on huperzine A molecule and its behavior in the active site, the molecule needs to be compared with the corresponding gas phase structure and the charge density distribution. In view of this, the structure, conformation, charge density distribution and the electrostatic properties of huperzine A in the gas phase is also essential. The comparative study between both forms (gas phase and active site forms) of huperzine A could reveal the degree of structure and the conformation of huperzine A modified when it present in the active site and the charge density distribution as well. For the past two decades, several studies have been performed to understand the interactions between AChE and Huperzine A using experimental and computational methods [25-29]. Notably, a recent study [30] explores the efficacy of huperzine A from the studies of thermodynamic and kinetic aspects, and concurrently, it also reports that the drug efficacy does not linearly correlate with binding affinity [31]. The most possible binding pathway of Huperzine A is gorge of TcAChE, which is also confirmed from energy landscape theory [30]. The AChE also exhibits a conformational flexibility [32] and the active site of AChE was rearranged by the influence of huperzine A $[33,34]$.

In the present study, a molecular docking analysis on huperzine A molecule has been carried out which allows to understand its conformational flexibity and the intermolecular 
interactions in the active site of AChE. Further, a quantum chemical calculation and the charge density analysis were performed for the huperzine A molecule lifted from the active site gives its charge density distribution and the electrostatic properties. On the other hand, a gas phase calculation on huperzine A molecule also carried out to compare its conformation and charge density distribution with the above said active site parameters. This comparative study insights the molecular conformational flexibility and the charge density distribution and the electrostatic properties of huperzine $\mathrm{A}$ in the active site, where the amino acids are interact with the huperzine A molecule as well. The charge density analysis of huperzine A molecule has been carried out for the molecule lifted from the active site of AChE obtained from the huperzine A-AChE docked complex. The toxicity also determined from the global reactivity descriptors such as electronegativity, electrophilicity and chemical hardness [3537] using density functional theory [38], which provides the essential information about the stability and reactivity of the molecule $[39,40]$.

\section{Results and Discussion}

\subsection{Molecular docking and Huperzine A-AChE Interactions}

The molecular docking of plant derived huperzine A molecule has been docked the active site of AChE, the docked lowest binding energy of the molecule is $-8.46 \mathrm{kcal} / \mathrm{mol}$ (Table S1). This energy is relatively lower than the docked binding energy of galanthamine and curcumin [56] with AChE; the low value of binding energy explicity indicates that huperzine A lacks some expected interactions with the AChE. Figure 1(a,b) displays the interaction between huperzine $\mathrm{A}$ and the nearby aminio acids present in the active site of AChE. 
Huperzine $\mathrm{A}$ is a three ring molecule, in which the rings 1 and $1^{\prime}$ are the two cyclohexene rings called as bicylo[3.3.1]nona-2,6-diene; and the ring 2 is a pyridone ring. Nitrogen of the pyridone ring forms hydrogen bonding interaction with Tyr130 at the distance $3.21 \AA$. The distance of the piperidinic nitrogen of huperzine $\mathrm{A}^{1}$ with the centroids of the aromatic ring of Trp84 is $4.49 \AA$; the longer distance indicates that the molecule does not exhibit strong interaction with Trp84. And further, the carbonyl group of the huperzine A molecule also forms strong hydrogen bonding interaction with the hydroxyl oxygen of the residue Tyr130 at the distance $2.88 \AA$. An electrostatic interaction is found between the bicyclo ring and the oxygen of main chain of Phe330 at the distances 3.02 and $3.25 \AA$ respectively. Apart from the above strong interactions, a large number of hydrophobic interactions also present with the side chains and the main chain atoms of Gly119 and His440 residues. Huperzine A has three potential hydrogen bonding sites, but only one interactive hydrogen bond is exist between the pyridone oxygen of the ligand and the hydrogen of the hydroxyl group of Tyr130 at the distance $2.88 \AA$. The nitrogen in the bicycle ring does not form any specific interaction. The atom $\mathrm{C}(12)$ of the same ring has hydrophobic interaction with the nitrogen group of the Gly119 at the distance $3.08 \AA$. Here, huperzine A interacts only with Phe330; this shows that the huperzine A binds only with acyl binding pocketPhe330 and not with the choline binding site-Trp84. Even at the acyl binding pocket-Phe330, it has a repulsive type of electrostatic interaction with the carbon atoms [49]. The nearest neighbours and the short contact distances below $3.3 \AA$ A between huperzine A molecule and the residues of AChE in the active site are presented (Table 2).

\subsection{Structural Analysis}

Figure 2(a,b) shows the ball and stick model of gas phase (I) and the active site form of huperzine A molecule (II) with the atom numbering scheme. The geometric parameters almost match with the reported structure [57] (hereafter the * indicates, the active site form 
of huperzine A molecule (II)). The $\mathrm{C}(1)-\mathrm{C}(2)$ bond distances of the ring 1 of (I) and (II) are: $1.549,1.556^{*} \AA$ respectively and in ring $1^{\prime}$, the $\mathrm{C}(5)-\mathrm{C}(11)$ bond distances are: $1.554,1.524^{*}$ $\AA$ respectively. The $\mathrm{C}_{\mathrm{sp} 3}-\mathrm{C}_{\mathrm{sp} 2}$ bond distances of the ring 1 and 1 ' of both forms (I \& II) are ranges $1.506-1.536 / 1.485^{*}-1.567 * \AA$, the average values are $1.521,1.526^{*} \AA$, respectively. The $\mathrm{C}_{\mathrm{sp} 2}-\mathrm{C}_{\mathrm{sp} 2}$ bond distances of ring 2 are found to be shorter than ring 1 , the corresponding gas phase and the active site distances are: $1.439,1.430 * \AA$, respectively. The $\mathrm{C}_{\mathrm{sp} 2}=\mathrm{C}_{\mathrm{sp} 2}$ bond distances of ring 1' $[\mathrm{C}(9)-\mathrm{C}(10): 1.335 / 1.337 * \AA]$ and the ring $2\left[\mathrm{C}(4)-\mathrm{C}(3): 1.370 / 1.395^{*}\right.$ $\AA$; $\mathrm{C}(14)-\mathrm{C}(15): 1.362 / 1.357^{*} \AA$ ] are relatively shorter than all other $\mathrm{C}-\mathrm{C}$ bonds in both forms of the molecule. The $\mathrm{C}_{\mathrm{sp} 2}-\mathrm{C}_{\mathrm{sp} 3}[\mathrm{C}(7)-\mathrm{C}(8)$ and $\mathrm{C}(10)-\mathrm{C}(12)]$ bonds of (I) and (II), adjoins the methyl group exhibit almost similar distances, the corresponding values ranges $1.502-1.505 / 1.488 *-1.513 * \AA$ respectively; these values are almost close to the reported [57] similar bonds [1.492 and $1.510 \AA$ ]. The carbonyl $\mathrm{C}=\mathrm{O}$ bond distance of $(\mathrm{I})$ is $1.223 \AA$, this distance has been increased to $1.256^{*} \AA$ A when huperzine A present in the active site. The gas phase $\mathrm{C}-\mathrm{N}$ distances of pyridone ring are found to be unequal $[\mathrm{C}(3)-\mathrm{N}(2): 1.368 \AA$, $\mathrm{C}(13)-\mathrm{N}(2): 1.411 \AA$ ] ; these distances are significantly altered when the molecule present in the active site; in which, the $\mathrm{C}(3)-\mathrm{N}(2)$ bond distance increases to $1.397 * \AA$ whereas the $\mathrm{C}(13)-\mathrm{N}(2)$ decreases to $1.313^{*} \AA$; this large $\mathrm{C}-\mathrm{N}$ distance variation is not found in the amine $\mathrm{NH}_{2}$ group attached $\mathrm{C}-\mathrm{N}$ bonds, as the distance varies from 1.465 to $1.476^{*} \AA$.

The $\mathrm{C}-\mathrm{C}-\mathrm{C}$ bond angles of ring $1,1^{\prime}$ are ranges from $107.1^{\circ}-113.9^{\circ} / 107.0^{\circ} *-114.5^{\circ} *$, the average values are $110.5^{\circ}$ and $110^{\circ} *$ respectively. The bond angles of $\mathrm{C}-\mathrm{C}-\mathrm{N}$ bond connected to the adjoint of ring 1 and $1^{\prime}$ of (I)/(II) forms are: $\mathrm{C}(6)-\mathrm{C}(5)-\mathrm{N}(1)$ : $116.3^{\circ} / 112.3^{\circ *} ; \quad \mathrm{C}(4)-\mathrm{C}(5)-\mathrm{N}(1): 107.9^{\circ} / 110.3^{\circ *}$ and $\mathrm{C}(11)-\mathrm{C}(5)-\mathrm{N}(1): 107^{\circ} / 107.1^{\circ *}$; whereas in ring 2 the bond angles are: $\mathrm{C}(2)-\mathrm{C}(3)-\mathrm{N}(2): 116.7^{\circ} / 116.6^{\circ}, \mathrm{C}(4)-\mathrm{C}(3)-\mathrm{N}(2)$ : $119.4^{\circ} / 119.2^{\circ *}$ and $\mathrm{C}(14)-\mathrm{C}(13)-\mathrm{N}(2): 112.4^{\circ} / 115.8^{\circ *}$. The $\mathrm{C}-\mathrm{N}-\mathrm{C}$ bond angle of ring 2 is $126.8^{\circ} / 124.6^{\circ} *$. The $\mathrm{N}-\mathrm{C}-\mathrm{O}$ and $\mathrm{C}-\mathrm{C}-\mathrm{O}$ bond angles of the same ring are: $[\mathrm{N}(2)-\mathrm{C}(13)-$ 
$\mathrm{O}(1)] 120^{\circ} / 120.3^{\circ} *$ and $[\mathrm{C}(14)-\mathrm{C}(13)-\mathrm{O}(1)] 127.6^{\circ} / 124^{\circ} *$ respectively; the active site $\mathrm{C}-\mathrm{C}-$ $\mathrm{O}$ bond angle of Huperzine A increased significantly, the difference is $3.6^{\circ}$.

Huperzine A molecule is found to be highly twisted when it present in the active site. This can be well understood when comparing the torsion angles of active site form of huperzine A (II) with the corresponding its gas phase structure (I). Particularly, in ring 1 and $1^{\prime}$, the gas phase torsion angle of $C(3)-C(2)-C(1)-C(6)$ and $C(2)-C(1)-C(6)-C(7)$ bonds are $-47.7^{\circ}$ and $-110.7^{\circ}$ respectively; whereas, in the active site the corresponding angles are $6.7^{\circ} *$ and $-90.5^{\circ} *$ respectively. Similarly, in the active site, a large bond twist also noticed in the methyl group attached $\mathrm{C}(8)-\mathrm{C}(7)-\mathrm{C}(6)-\mathrm{C}(1)$ bonds, the torsion angle is $16.4^{\circ *}$; this angle is found to be much higher than the corresponding angle in gas phase $\left(-0.5^{\circ}\right)$. The other most affected bonds in the active site are: $\mathrm{C}(9)-\mathrm{C}(1)-\mathrm{C}(6)-\mathrm{C}(7)\left[127.8^{\circ} / 145.9^{\circ *}\right]$, $\mathrm{C}(7)-\mathrm{C}(6)-\mathrm{C}(5)-\mathrm{C}(4)\left[127.1^{\circ} / 106.6^{\circ *}\right]$ and $\mathrm{C}(7)-\mathrm{C}(6)-\mathrm{C}(5)-\mathrm{C}(11)\left[-114.3^{\circ} /-133.3^{\circ *}\right]$; notably, these are the highly twisted bonds in the huperzine A molecule, when it present in the active site of AChE. And further, there are twist in the other bonds of the huperzine A molecule also noticed (Table S2), these large bond twists in the active site are mainly attributed to the intermolecular interactions and the energy of the huperzine A molecule in the active site of AChE.

\subsection{Charge Density Analysis}

The electron density distribution of huperzine A molecule has been studied using the Bader's theory of atoms in molecules (AIM) [46,47]. The electron density $\rho_{b c p}(r)$, the Laplacian of electron density $\nabla^{2} \rho_{b c p}(r)$, eigen values and bond ellipticity at the bond critical point (bcp) were determined for both forms [gas phase (I) and active site (II)] of huperzine A molecule. In figure 3, (a,b) shows the deformation density maps of (I) and (II) forms of huperzine A molecule respectively. The topological properties of electron density $\rho b c p(r)$ of 
both forms [(I) and (II)] are presented in table 2. The deformation density map allows to visualize the areas of charge accumulation and the lone pair position of atoms in both forms of huperzine A molecule. A critical point search has been performed for all bonds of the molecule, predicted a $(3,-1)$ type of critical point for all bonds, which confirms the covalent sharing bonds are present in the molecule.

The electron density $\rho b c p(r)$ of $\mathrm{C}-\mathrm{C}$ bonds of ring1, 1' are found to be almost similar in both forms of molecule (I)/(II) $\left[1.656 / 1.683 * \mathrm{e}^{-3}\right]$; relatively, these values are much less than the density of $\mathrm{C}-\mathrm{C}$ bonds of ring 2 , the corresponding average values are: $1.941 / 1.975^{*}$ $\mathrm{e}^{-3}$. Despite the charge transfer from the hydrogen atoms to carbon atoms of the ring 2 , large charge accumulation is found near the hydrogen atom [58]. Invariably, the charge concentration in $\mathrm{C}(9)-\mathrm{C}(10): 2.304 / 2.295 * \mathrm{e}^{-3}, \mathrm{C}(6)-\mathrm{C}(7): 2.285 / 2.430 * \mathrm{e} \AA^{-3}, \mathrm{C}(3)-\mathrm{C}(4)$ : 2.177/2.071* $\mathrm{e} \AA^{-3}$ and $\mathrm{C}(14)-\mathrm{C}(15): 2.202 / 2.230 * \mathrm{e}^{-3}$ bonds are found to be higher than all other $\mathrm{C}-\mathrm{C}$ bonds in both forms of the molecule. The electron density of high polar $\mathrm{C}=\mathrm{O}$ bond in gas phase is $2.74 \mathrm{e}^{-3}$; this value has been slightly decreased [2.569* $\left.\mathrm{e}^{-3}\right]$ when it present in the active site. The gas phase value is well agree with the reported values [59-61]. The $\rho_{b c p}(r)$ value of $C(10)-C(12)$ and $C(7)-C(8)$ bonds which are linked to the methyl group are: 1.703 and $1.696 \mathrm{e}^{-3}$ respectively; whereas in (II), these values are found to be $1.678^{*}$ and $1.743 * \mathrm{e} \AA^{-3}$ respectively. The electron density of $\mathrm{C}(5)-\mathrm{N}(1)$ bond in I and II are: $1.792 / 1.760 * \mathrm{e}^{-3}$; these values are relatively less on compared with the $\mathrm{C}(3)$ $\mathrm{N}(2)\left[2.081 / 1.950 * \AA^{-3}\right]$ and $\mathrm{C}(13)-\mathrm{N}(2)\left[1.923 / 2.091 * \mathrm{e}^{-3}\right]$ bonds in the molecule. The difference of charge accumulation in both $\mathrm{C}-\mathrm{N}$ bonds is attributed to the nature of different environments. The electron density of these $\mathrm{C}-\mathrm{N}$ bonds is not much affected in the active site, as the difference of density is found to be very small.

The Laplacian of electron density $\nabla^{2} \rho_{b c p}(r)$ of all bonds of (I) and (II) forms of huperzine A have been calculated (Table 2). Figure S1 displays the Laplacian of electron 
density distribution of huperzine A molecule. The Laplacian for the $\mathrm{C}-\mathrm{C}$ bonds of rings 1 and 1 ' are ranges from -11.9 to $-14.8 /-11.5 *$ to $-15.8^{*} \mathrm{e}^{-5}$, the average are $-13.5 /-13.9 * \mathrm{e} \AA^{-5}$; these values are notably less on compared with the Laplacian of $\mathrm{C}-\mathrm{C}$ bonds of ring 2 , the corresponding values are $-18.35 /-19.1 * \mathrm{e}^{-5}$. The Laplacian of $\mathrm{C}=\mathrm{C}$ bonds $[\mathrm{C}(9)-\mathrm{C}(10)$ :23.9/-23.7* $\mathrm{e}^{-5}, \mathrm{C}(6)-\mathrm{C}(7):-23.3 /-26.7^{*} \quad \mathrm{e} \AA^{-5}, \mathrm{C}(3)-\mathrm{C}(4):-21.9 /-19.5^{*} \quad \mathrm{e} \AA^{-5}$ and $\left.\mathrm{C}(14)-\mathrm{C}(15):-22.6 /-23.2 * \mathrm{e}^{-5}\right]$ of (I)/(II) are found to be high. In the active site, relatively, the Laplacian of $\mathrm{C}(6)-\mathrm{C}(7)$ bond was increased, whereas in $\mathrm{C}(3)-\mathrm{C}(4)$ bond, this value has been slightly decreased. The gas phase (I) Laplacian value of the carbonyl $\mathrm{C}=\mathrm{O}$ bond is -8.3 $\mathrm{e} \AA^{-5}$, while the corresponding active site (II) value is, $-13.5^{*} \mathrm{e} \AA^{-5}$; the increase of negative Laplacian in (II) indicates that the charges of the bond become concentrated in the active site. In (I), the Laplacian value of methyl group connected $\mathrm{C}(10)-\mathrm{C}(12)$ and $\mathrm{C}(7)-\mathrm{C}(8)$ bonds are -14.4 and $-14.3 \mathrm{e} \AA^{-5}$ respectively; whereas in (II), the corresponding values are $-14.0^{*}$ and $15.2^{*} \mathrm{e} \AA^{-5}$ respectively. In both forms, the Laplacian of $\mathrm{C}-\mathrm{N}$ bonds are found to be moderately negative (Table 2), indicates, the Laplacian values are not much affected when the molecule present in the active site except $\mathrm{C}(13)-\mathrm{N}(2)$ bond $\left[\mathrm{C}(5)-\mathrm{N}(1)\right.$ : $-16.5 /-15.7^{*}$, $\mathrm{C}(3)-\mathrm{N}(2):-18.7 /-17.7^{*}$ and $\left.\mathrm{C}(13)-\mathrm{N}(2):-18.2 /-20.3 * \mathrm{e} \AA^{-5}\right]$, in which the charges are become concentrated. Figure 5 displays the variation of charge concentration at the bcp's of huperzine $\mathrm{A}$ in the active site of $\mathrm{AChE}$.

The deformation density signifies the aspherical nature of electron density of atoms in the molecule, which is attributed to the bond formation. The features such as spherical/aspherical nature of electron density of bonds can be qualitatively interpreted in terms of bond ellipticity [61]. Bond ellipticity $\varepsilon\left[\varepsilon=\left(\lambda_{1} / \lambda_{2}\right)-1\right]$ is the measure of degree of planarity or conjugation of electron density at the bcp, where $\lambda_{1}$ and $\lambda_{2}$ are the Hessian eigen values of electron density at the bcp's [62]. The lower values of electron density and the Laplacian of electron density together with high ellipticity are the indicative of the charge 
migration to the neighbouring bonds [63]. In the present study, the ellipticity $\varepsilon$ of $\mathrm{C}-\mathrm{C}$ bonds of the pyridone ring of both forms [(I) \& (II)] is $\quad$ 0.16; these values are found to be high, when compared with all other $\mathrm{C}-\mathrm{C}$ bonds in the molecule (figure 4). The ellipticity of $\mathrm{C}=\mathrm{C}$ bonds is $\sim 0.3$; this high $\varepsilon$ value indicates the degree of aspherical electron density distribution. All the other bonds in the molecule exhibit less ellipticity (Table 2), reveals the spherical electron density distribution.

\subsection{Atomic Charges, Dipole Moment and Electrostatic Potential}

The atomic charges of both forms (I \& II) of huperzine A were calculated from Mulliken (MPA) [64] and natural population analysis (NPA) [65] and Bader's AIM analysis [47] (Table S3). Notably, the Bader's AIM charges are found to be higher than the MPA and NPA charges for all atoms. Generally, the carbon atoms, which are attached to the negatively charged atoms, carry high positive charge. The AIM charges of C-atoms of (I) and (II) forms are: $\quad \mathrm{C}(3): 0.41 \mathrm{e} / 0.36 \mathrm{e}^{*}, \mathrm{C}(5): 0.37 \mathrm{e} / 0.35 \mathrm{e}^{*}$ and $\mathrm{C}(13): 1.31 \mathrm{e} / 1.28 \mathrm{e}^{*}$, these charges are relatively high on compared with the MPA and NPA charges, the difference is attributed to the different definition of atoms in the molecule. The AIM model predicts high negative charges for the polar oxygen and nitrogen atoms $\left[\mathrm{O}(1):-1.15 \mathrm{e} /-1.12 \mathrm{e}^{*} ; \mathrm{N}(1)\right.$ : 0.96e/-0.97e*; N(2): -1.13e/-1.15e*].

The predicted active site dipole moment of huperzine A molecule is 6.85 Debye, which is found to be higher than the same found in the gas phase (5.91 Debye), the small enhancement of dipole moment of huperzine $A$ in the active site is due to the charge redistribution in the molecule caused by the effect of intermolecular interaction between the two molecules. Figure 5 shows the superimposed form of (I) and (II) forms of huperzine A molecule, which displays the orientation of dipole moment vectors of huperzine $\mathrm{A}$ in gas phase (I) and in the active site (II). The deviation of dipole moment vector of (II) with respect to (I) is solely attributed to the conformational change as well as charge redistribution. The 
net dipole moment of (I) and (II) forms of huperzine A and its $\mathrm{x}, \mathrm{y}, \mathrm{z}$ component values are presented in Table 3.

Figure 6(a,b) shows the molecular electrostatic potential (ESP) of the huperzine A molecule in gas phase (I) and the same molecule lifted from the active site (II) of AChE. In the drug-receptor interaction, it is important to recognize that both the three dimensional shape and the electronic characteristics of the drug molecule are seldom important [66]. The ESP of (I) and (II) are found to be almost equal; however, between the two forms, a slight difference is observed, figure 8 displays the exact difference; perhaps this may be due to less electron density redistribution in the molecule when it present in the active site, which kept the ESP remains almost same. A large electronegative region is found at the vicinity of $\mathrm{O}(1)$ and $\mathrm{N}$-atoms in both forms of the molecule. Figure $8 \mathrm{~b}$ is the pictorial representation of intermolecular interaction shows some important interactions; in which, particularly the $\mathrm{N}(2)$ atom forms hydrogen bonding interaction with Tyr130. As expected, the $\mathrm{O}(1)$ atom forms hydrogen bonding interaction with amino acid residue [1,12] Tyr130; further, the same oxygen $\mathrm{O}(1)$ also forms electrostatic interaction [49] with Gly117.

\subsection{Toxicity Analysis}

The toxicity of huperzine A molecule have been analyzed from global reactivity descriptors such as electronegativity $(\chi)$, electrophilicity $(\omega)$ and chemical hardness $(\eta)$. In both forms, the ionization potential ( $\mathrm{I}=-\mathrm{E}$ номо $)$ and electron affinity $\left(\mathrm{A}=-\mathrm{E}_{\mathrm{LUMO}}\right)$ of huperzine A molecule were calculated from HOMO and LUMO energy values (Table 4). The ionization potential and electron affinity values are 5.72/5.62* and 1.04/1.1* respectively. The huperzine A molecule has low electronegativity $\left(3.38 / 3.36^{*}\right)$ on compared with ionization potential; hence the molecule has fewer tendencies to accept electrons in both forms. The global hardness of the molecule is $2.34 / 2.26^{*}$ respectively; it reveals that the molecule is stabilized in the active site. The calculated electrophilicity index of both forms is 
$2.44 / 2.49 *$ respectively; this value indicates that the charge transfer of the molecule is low. The gobal reactivity descriptors have not much varied in the gas phase as well as in the active site. From this analysis, we have distinctly confirmed that the huperzine A molecule has low toxicity, high stability when the molecule present in the active site of $\mathrm{AChE}[23,67]$.

\section{Materials and Methods}

\subsection{Calculations}

To precisely understand the effect of intermolecular interaction of huperzine A molecule in the active site, it is essential to compute the parameters like molecular conformation, charge density distribution and the electrostatic properties of the molecule in the gas phase as well as in the active site. Hence, the computational calculations were performed in two parts. In the first part, the gas phase (at $\mathrm{T}=298.15 \mathrm{~K}, \mathrm{P}=1 \mathrm{~atm}$ ) of huperzine A molecule (I) was optimized from HF [41] and DFT (B3LYP) [42,43] methods with the basis set 6-311G** using Gaussion03 software [44,45]; in which the threshold limit for maximum force and displacement of DFT optimization were converged at 0.000004 and 0.000257au respectively. Further, a charge density analysis has been carried out using Bader's theory $[46,47]$ of atoms in molecules (AIM). In the second part, a molecular docking analysis of huperzine A with AChE has been carried out using Autodock software [48, 49]. For the docking analysis, the ligand was obtained by separating the same from the complex domain of pdb accession code 1VOT [1] and converted into pdb format, whereas the threedimensional structure of AChE of "Torpedo californica" was prepared by separating AChE form the complex domain of pdb accession code 1QTI [50] obtained from Brookhaven Protein Data Bank. Autodock generated 10 different conformations and their corresponding docked energies (Table S1). PyMOL [51] software was used to view the huperzine A-AChE complex and the intermolecular interactions between the AChE and huperzine A. Further, a single point energy DFT calculation was carried out for the huperzine A molecule (lowest 
energy conformer) lifted from the huperzine A-AChE docked complex at B3LYP/6-311G** level; and further a charge density analysis has been performed for the wave function obtained from the single point energy calculation.

From the charge density analysis, the bond topological properties, such as total electron density, deformation density, Laplacian of electron density, bond ellipticity at the bond critical points, eigen values $\left(\lambda_{1}, \lambda_{2}, \lambda_{3}\right)$ and the bond path were determined from the Bader's theory [46,47] of atoms in molecules implemented in AIMPAC software [52]. The AIM charges were calculated from AIMALL software [53]. The deformation density of both forms [(I) and (II)] of the molecule were plotted by wfn2plots and XD software [54]. A cube file was generated from Gaussian03, which has been used as an input file for the Moliso program suite [55] to generate the electrostatic potential (ESP) map.

\section{Conclusion}

The geometrical and topological properties of electron density of the huperzine A molecule in gas phase and the same lifted from the active site have been compared. This comparative study explores the conformational modification, intermolecular interaction, charge density distribution and the electrostatic properties of the molecule in the active site of AChE. The lowest binding energy of huperzine A in the active site of AChE is -8.46 $\mathrm{kcal} / \mathrm{mol}$. In the huperzine $\mathrm{A}$, the $\mathrm{O}(1)$ atom forms hydrogen bonding interaction with Tyr130 and electrostatic interaction with Gly117, whereas the nitrogen $\mathrm{N}(2)$ has hydrogen bonding interaction with Tyr130 only. The carbon $\mathrm{C}(8)$ forms electrostatic interaction with the residue Phe330, which shows that the molecule binds at the acyl binding pocket, which leads huperzine A to inhibit AChE. For the molecule lifted out from the active site, it is found that the geometry of ring 1, 1' are modified, whereas in ring 2, the geometry is not much altered, it is almost intact. Further, the charges are redistributed and it is found high in polar bonds. The dipole moment of the molecule in the active site is 6.85 Debye, which is higher than its 
gas phase value (5.91 Debye). Large electronegative ESP regions are found at the vicinity of $\mathrm{O}$ and $\mathrm{N}$-atoms in I and II forms of the molecule, in which, the oxygen and nitrogen atoms of (II) are exhibit high negative ESP as it is less in the gas phase. The present active site charge density study of huperzine A has been performed for the molecule lifted from the active site of AChE; hence, as expected it does not include the polarization effect.

Acknowledgement. A. R. P. thanks Jawaharlal Nehru Memorial Fund, New Delhi, India, for the scholarship to carry out this research work.

\section{References}

1. Raves, M.L; Harel, M; Pang, Y.P; Silman, I; Kozikowski, A.P; Sussman, J.L. Structure of acetylcholinesterase complexed with the nootropic alkaloid, (-)huperzine A. Nat Struct Biol. 1997, 4, 57-63.

2. Liu, J.S; Zhu, Y.L; Yu, C.M; Zhou, Y.Z; Han, Y.Y; Wu, F.W; Qi, B.F. The structures of huperzine $\mathrm{A}$ and $\mathrm{B}$, two new alkaloids exhibiting marked anticholinesterase activity. Can J Chem. 1986, 64, 837-839.

3. Darvesh, S; Walsh, R; Martin, E. Enantiomer effects of Huperzine A on the aryl acylamidase activity of Human cholinestereses. Cell Mol Neurobiol. 2003, 23, $93-$ 100.

4. Zhang, H.Y; Yan, H; Tang, X.C. Non-cholinergic effects of Huperzine A: Beyond inhibition of acrtylcholinesterase. Cell Mol Neurobiol. 2008, 28, 173-183.

5. Meng, Z.L; Sun, A.L; Liu, R.M; Wang, D.Q. (6R,10R,14E)-6-Amino-12-ehtylidene8-methyl-6,7,10,12-tetrahydro-6,10-methanocycloocta[b]-pyridin-2(1H)-one monohydrate. Acta Cryst E. 2006, 62, o4911-04912.

6. Tan, C.H; Chen, G.F; Ma, X.Q; Jiang, S.H; Zhu, D.Y. Huperzine R, a novel 15-Carbon Lycopodium alkaloid from Huperzia serrata. J. Nat.Prod. 2002, 65, 1021-1022. 
7. Tan, C.H; Ma, X.Q; Chen, G.F; Jiang, S.H; Zhu, D.Y. Two novel Lycopodium alkaloids from Huperzia serrata. Helvetica Chemica Acta. 2002, 85, 1058-1061.

8. Maclean, D.B. Lycopodium alkaloids Xiii. Mass spectra of representative Alkaloids. Can. J. Chem. 1963, 41, 2654.

9. William, A.A; Browne, L.M; Orszanska. Alkaloids of Lycopodium selago. On the identity of selagine with hyperzine A and the structure of a related alkaloid. Can. J. Chem. 1989, 67, 1538-1540.

10. Youshimura, H; Valenta, Z; Wiesner, K. A rigorous proof of the selegaine structure. Tetrahedron Lett. 1960; 12: 14-17.

11. Ma, X; Gang, D.R. The Lycopodium alkaloids. Nat. Prod. Rep. 2004, 21, 752-772.

12. Wang, R; Yan, H; Tang, X.C. Prograss in studies of huperzine A, a natural cholinesterase inhibitor from Chinese folk medicine. Acta Pharmacol Sin. 2006, 27, $1-26$.

13. Zhang, H.Y; Tang, X.C. Neuroprotective effects of huperzine A: new therapeutic targets for neurodegenerative disease. TRENDS in Pharamacol. Sci. 2006, 27, 619625.

14. Ha, G.T; Wong, R.K; Zhang, Y. Huperzine A as potential treatment of Alzheimer disease: an assessment on chemistry, pharmacology and clinical studies. Chem Biodivers. 2011, 8, 1189-1204.

15. Cheng, D.H; Ren, H; Tang, X.C. Huperzine A, a novel promising acetylcholinesterase inhibitor. Neuroreport. 1996, 8, 97-101.

16. Ashani, Y; Grunwald, J; Kronman, C; Velan, B; Shafferman, A. Role of Tyrosine 337 in the Binding of Huperzine A to the Active Site of Human Acetylinesterase. Mol Pharmacol. 1994, 45, 555-560. 
17. Wang, B.S; Wang, H; Wei, Z.H; Song, Y.Y; Zhang, L; Chen, H.Z. Efficacy and safety of natural acetylcholinesterase inhibitor huperzine A in the treatment of Alzheimer's disease: an updated meta-analysis. J Neural Transm. 2009, 116, 457465.

18. Tang, X.C; De Sarno, P; Sugaya, K; Giacobini, E. Effect of Huperzine A, a new cholinesterase inhibitor, on the central cholinergic system of the rat. J Neurosci Res. 1989, 24, 276-285.

19. Wang, R; Yan, H; Tang, X.C. Progress in studies of huperzine A, a natural cholinesterase inhibitor from Chinese herbal medicine. Acta Pharmacol Sin. 2006, $27,1-26$

20. Zhang, H.Y; Zheng, C.Y; Yan, H; Wang, Z.F; Tang, L.L; Gao, X; Tang, X.C. Potential therapeutic targets of huperzineA for Alzheimer's disease and vascular dementia. Chem Biol Interact. 2008, 175, 396-402.

21. Liang, Y.Q; Huang, X.T; Tang, X.C. Huperzine A Reverses cholinergic and Monoaminerfic dysfunction induced by bilateral nucleus basalis magnlcelllularis injection of $\beta$-Amyloid peptide (1-40) in Rats. Cell Mol Neurobiol. 2008, 28:87-101.

22. Coyle, J.T; Price, D.L; DeLong, M.R. Alzheimer's disease: a disorder of cortical cholinergic innervations. Science. 1983, 219, 1184-1190.

23. Weiliang, Z; Jiande, G.U; Hualiang, J; Jianzhong, C; Dongxiang, L; Maowei, L; Kaixian C; Ruyun, J. IR spectrum and normal mode analysis of the anti-Alzheimer's disease natural product Huperzine A: A quantum chemistry density-functional theory (DFT) investigation. Science in china. 1998, 41, 616-622.

24. Tang, X.C; Xiong, Z.Q; Qian, B.C; Zhou, Z.F; Zhang, C.L. Cognition improvement by oral Huperzine A: a novel acetlycholinestrase inhibitor in Alzheimer Disease. Advances in Alzheimer Disease Therapy. 1994, 113-119. 
25. Li, Y; Yin, G; Wei, W; Wang, H; Jiang, S; Zhu, D; Du, W. Interactions of Lycopodium alkaloids with acetylcholinesterase investigated by $1 \mathrm{H}$ NMR relaxation rate, Biophy. Chem. 2007, 129, 212-217.

26. Trapp, M; Trovaslet, M; Nachon, F; Koza, M.M; Eijck, L.V; Hill, F; Weik, M; Masson, P; Tehei, M; Peters, J. Energy Landscapes of Human acetylcholinesterase and its Huperzine A-inhibited counterpart. J. Phy. Chem. B. 2012, 116,14744-14753.

27. Trapp, M; Tehei, M; Trovaslet, M; Nachon, F; Martinez, N; Koza, M.M; Weik, M; Masson, P; Peters, J. Correlation of the dynamics of native human acetylcholinesterase and its inhibited huperzine A counterpart from sub-picoseconds to nanoseconds. J. R. Soc. Interface. 2014, 11, 20140372.

28. Khan, M.T.H. Molecular interactions of cholinesterase inhibitors using in silico methods: current status and future prospects. New Biotech. 2009, 25, 331-346.

29. Kitisripanya, N; Saparppakorn, P; Wolschann, P; Hannongbua, S. Binding of huperzine A and galanthamine to acetylcholinesterase based on ONIOM method. Nanomed Nanotech. Bio. Med. 2011, 7, 60-68.

30. Bai, F; Xu, Y; Chen, J; Liu, Q; Gu, J; Wang, X; Ma, J; Li, H; Onuchic, J.N; Jiang, H. Free energy landscape for the binding process of huperzine A to acetylcholinesterase. PANS. 2013, 1, 4273-4278.

31. Swinney, D.C. Biochemical mechanisms of drug action: what does it take for success? Nat. Rev. 2004, 3, 801-808.

32. Alberts, I.L; Todorov, N.P; Dean, P.M. Receptor flexibility in de novo ligand design and docking. J. Med. Chem. 2005, 48:6585-6596.

33. Bautonnet, N; Belle, D.V. Wodak SJ. Influence of ligand binding on the conformation of Torpedo californica acetylcholinesterase. Theor. Chem. Acc. 2001, 106, 10-21. 
34. Dvir, H; Jiang, H.L; Wong, D.M; Harel, M; Chetrit, M; He, X.C; Jin, G.Y; Yu, G.L; Tang, X.C; Silman, I; Bai, D.L. Sussman JL. X-ray structures of Torpedo californica acetylcholinesterase complexed with (+)-Huperzine A and (-)-Huperzine B: Structural evidence for active site rearrangement. Biochem. 2002, 41, 10810-10818.

35. Parr, R.G; Pearson, R.G. Absolute Hardness: Companion parameter to absolute electronegativity. J. Am. Chem. Soc. 1983, 105, 7512-7516.

36. Roy, D.R; Sarkar, U; Chattaraj, P.K; Mitra, A; Padmanabhan, J; Parthasarathi, R; Subramanian, V; Damme, S.V; Bultinck, P. Analyzing toxicity through Electrophilicity. Mol. Diver. 2006, 10, 119-131.

37. Parr, R.G; Szentpaly, L.V; Liu, S. Electrophilicity Index. J. Am. Chem. Soc. 1999, $121,1922-1924$.

38. Vijayaraj, R; Subramanian, V; Chattaraj, P.K. Comparison of global reactivity descriptors calculated using various density functional: a QSAR perspective. $J$. Chem. Theory. Comput. 2009, 5, 2744-2753.

39. Geerlings, P; Proft, F.D; Langencker, W. Conceptual density functional theory. Chem.Rev. 2003, 103, 1793-1873.

40. Roy, D.R; Parthasarathi, R; Maiti, B; Subramanian, V; Chattaraj, P.K. Electrophilicity as a possible descriptor for toxicity prediction. Bioorg. Med. Chem. 2005, 13, 3405-3412.

41. Leech, A.R. Molecular Modelling Principles and Applications, $2^{\text {nd }}$ ed.; Addison Wesley Longman; Essex: England; 2001.

42. Labanowski, J.K; Andzelm, J.W. Density Functional Methods in Chemistry. Springer; New York; 1991.

43. Parr, R.G; Yang, W. Density Functional Theory of Atoms and Molecules. Oxford; New York; 1989. 
44. Frisch, M.J; Trucks, G.W; Schlegel, H.B; Scuseria, G.E; Robb, M.A; Cheeseman, J.R; Montgomery, J.A; Vreven, T; Kudin, K.N; Burant, J.C; Millam, J.M; Iyengar, S.S; Tomasi, J; Barone, V; Mennucci, B; Cossi, M; Scalmani, G; Rega, N; Petersson, G.A; Nakatsuji, H; Hada, M; Ehara, M; Toyota, K; Fukuda, R; Hasegawa, J; Ishida, M; Nakajima, T; Honda, Y; Kitao, O; Nakai, H; Klene, M; Li, X; Knox, J.E; Hratchian, H.P; Cross, J.B; Adamo, C; Jaramillo, J; Gomperts, R; Stratmann, R.E; Yazyev, O; Austin, A.J; Cammi, R; Pomelli, C; Ochterski, J.W; Ayala, P.Y; Morokuma, K; Voth, G.A; Salvador, P; Dannenberg, J.J; Zakrzewski, V.G; Dapprich, S; Daniels, A.D; Strain, M.C; Farkas, O; Malick, D.K; Rabuck, A.D; Raghavachari, K; Foresman, J.B; Ortiz, J.V; Cui, Q; Baboul, A.G; Clifford, S; Cioslowski, J; Stefanov, B.B; Liu, G; Liashenko, A; Piskorz, P; Komaromi, I; Martin, R.L; Fox, D.J; Keith, T; Al-Laham, M.A; Peng, C.Y; Nanayakkara, A; Challacombe, M; Gill, P.M.W; Johnson, B; Chen, W; Wong, M.W; Gonzalez, C; Pople, J.A. Gaussian03; Revision D.1. Wallingford; CT: Gaussian; 2005.

45. Smith, S.J; Sutcliffe, B.T. The development of Computational Chemistry in the United Kingdom. Rev. Comp. Chem. 1997; 10, 271-316.

46. Bader, R.F.W; Tal, Y; Anderson, S.G; Nguyen-Dang, T.T. Quantum Topology: Theory of Molecular Structure and its Change. Isr. J. Chem. 1980, 19, 8-29.

47. Bader, R.F.W. Atoms in molecules: A Quantum Theory; International series of Monographs in chemistry 22; Oxford University. Press: Oxford; 1990.

48. Morris, G.M; Goodsell, R.S; Halliday, R.S; Huey, R; Hart, W.E; Belew, R.K; Olson, A.J. Automated Docking Using a Lamarckian Genetic Algorithm and Empirical Binding Free Energy Function. J.Comput. Chem. 1998, 19, 1639-1662.

49. Renuga Parameswari, A; Rajalakshmi, G; Devipriya, B; Palvannan, T; Kumaradhas, P. Understanding the Binding Modes and Affinities of Different Drug Molecules of 
Alzheimer Disease in Acetylcholinesterase Active Site Gorge: A Comparative Molecular Docking Study. Int. J. Pharma. Res. 2011, 3, 52-58.

50. Pilger, C; Bartolucci, C; Lamba, D; Tropsha, A; Fels, G. Accurate prediction of the bound conformation of galanthamine in the active site of "Torpedo californica" acetylcholinesterase using molecular docking. J. Mol. Graphics Modell. 2001, 19, 288-296.

51. DeLano, W.L; PyMol Molecular Graphics System. DeLano Scientific. San Carlos. CA. USA. 1998.

52. Cheeseman, J; Keith, T.A; Bader, R.F.W. AIMPAC Program Package McMaster University Hamilton. Ontario. 1992.

53. Keith, T.A. AIMALL (Version 09.02.01). Available at: aim@tkgristmill.com; 2009.

54. Koritsanszky, T; Macchi, P; Gatti, C; Farrugia, L.J; Mallinson, P.R; Volkov, A; Richter T. XD-2006. A Computer Program Package for Multipole Refinement and Topological Analysis of Charge Densities and Evaluation of Intermolecular Energies from Experimental or Theoretical Structure Factors. Version 5.33. 2007.

55. Hubschle, C.B; Luger, P. MolIso - a program for colour-mapped iso-surfaces. $J$. Appl. Crystallogr. 2006, 39, 901-904.

56. Abramov, Y.A; Brammer, L; Klooster, W.T; Morris Bullock, R. Experimental Charge Density and Neutron Structural Study of cis-HMn(CO)4 $\mathrm{PPh}_{3}$; Comprehensive Analysis of Chemical Bonding and Evidence for a $\mathrm{C}-\mathrm{H} \cdots \mathrm{H}-\mathrm{Mn}$ Hydrogen Bond. Inorg Chem. 1998, 37, 6317-6328.

57. Geib, S.J; Tuckmantel, W; Kozikowski, A.P. Huperzine A-a potent acetylcholinesterase inhibitor of use in the treatment of Alzheimer's disease. Acta Cryst C. 1991, 47: 824-827. 
58. Lecomte, C; Souhassou, M; Pillet, S. Topology of experimental charge density: a tool for understanding atomic interactions. J. Mol. Struct. 2003, 647, 53-64.

59. Chopra, D; Cameron, T.S; Ferrara, J.D; Guru Row, T.N. Pointers toward the occurrence of $\mathrm{C}-\mathrm{F} \cdots \mathrm{F}-\mathrm{C}$ interaction: Experimental charge density analysis of 1-(4fluorophenyl)-3;6;6-trimethyl-2-phenyl-1;5;6;7-tetrahydro-4H-indol-4-one and 1-(4fluorophenyl)-6-methoxy-2-phenyl-1;2;3;4-tetrahydroisoquinolin. J. Phys. Chem. A. 2006, 110, 10465-10477.

60. Munshi, P; Guru Row, T.N. Intra- and intermolecular interactions in small bioactive molecules: cooperative features from experimental and theoretical charge-density analysis. Acta Cryst B. 2006, 62, 612-626.

61. Devipriya, B; Renuga Parameswari, A; Rajalakshmi, G; Kumaradhas, P. Charge Density Distribution and Electrostatic Moments of $N$-(4-Chloro-3- trifluromethylphenyl)-2-ethoxy-benzamide Molecule at the Active Site of p300 Enzyme: A Quantum Chemical and Theoretical Charge Density Study. Int. J. Quant. Chem. 2006, 112, 1185-1197.

62. Popelier, P.L.A. Atoms in Molecules an Introduction. Pearson Edition: Harlow. U. K. 1999.

63. Thomas, R; Lakshmi, S; Pati, S.K; Kulkarni, G.U. Role of triple bond in 1;2diphenylacetylene crystal: A combined experimental and theoretical study. J. Phys. Chem. B. 2006, 110, 24674-24677.

64. Mulliken, R.S. Electronic Population Analysis on LCAO-MO Molecular Wave Functions. J. Chem. Phys. 1955, 23, 1833-1841.

65. Reed, A.E; Weinstock, R.B; Weinhold, F.A. Natural population analysis. J.Chem. Phys. 1985, 83, 735-747. 
66. Zhu, N; Cheryl, L; Stevens, K; Edwin, D; Zhu, N; Klein Stevens, K.L; Stevens, E.D. An Experimental Charge Density Study of Mesulergine Hydrochloride; a Dopamine Agonist. J. Chem. Cryst. 2005, 35, 13-22.

67. Wang, Y; Wei, Y; Oguntayo, S; Doctor, B.P; Nambiar, M.P. A combination of [+] and [-]-Huperzine A improves protection against soman toxicity compared to [+]Huperzine A in guinea pigs. Chemico-Biological Interact. 2013, 203, 120-124.

(C) 2016 by the authors; licensee Preprints, Basel, Switzerland. This article is an open access article distributed under the terms and conditions of the Creative Commons by Attribution (CC-BY) license (http://creativecommons.org/licenses/by/4.0/). 